\title{
Adubação foliar de boro em diferentes estádios fenológicos da cultura do amendoim ${ }^{1}$
}

\author{
João Paulo Machado Mantovani ${ }^{2}$, Juliano Carlos Calonego ${ }^{3}$, José Salvador Simonetti Foloni ${ }^{4}$
}

\begin{abstract}
RESUMO
A adubação boratada foliar, na cultura do amendoim, pode ser uma estratégia viável para fornecimento desse elemento à planta; porém, são poucos os conhecimentos sobre dosagens, épocas e efeitos de parcelamento das doses. O objetivo deste trabalho foi avaliar as características de produção e a composição mineral foliar em diferentes doses, épocas de aplicação e parcelamentos da adubação boratada. O experimento foi conduzido na safra de verão 2010/2011, em Latossolo Vermelho distroférrico, em Rubiácea (SP). Foram estudadas as doses de zero; 0,5; 1,0; 1,5e 2,0 $\mathrm{kg} \mathrm{ha}^{-1} \mathrm{de}$ boro (B), aplicadas por via foliar, utilizando-se como fonte o ácido bórico. Os efeitos da adubação boratada foram testados em doses únicas nos estádios V1 ou R5, além do parcelamento da dose de 1,0 $\mathrm{kg} \mathrm{ha}^{-1}\left(0,5 \mathrm{~kg} \mathrm{ha}^{-1} \mathrm{em} \mathrm{V1} \mathrm{e} \mathrm{R5),}\right.$

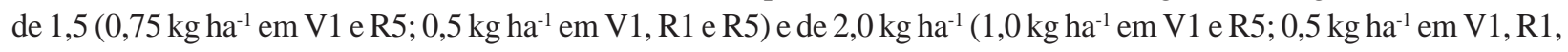
$\mathrm{R} 3 \mathrm{e}$ R5). O aumento na produtividade de amendoim em casca ocorreu apenas com a dose de $1,5 \mathrm{~kg} \mathrm{ha}^{-1}$, parcelada em três aplicações de 0,5 $\mathrm{kg} \mathrm{ha}^{-1} \mathrm{em} \mathrm{V1,} \mathrm{R1} \mathrm{e} \mathrm{R5.} \mathrm{A} \mathrm{utilização} \mathrm{de} \mathrm{2,0} \mathrm{kg} \mathrm{ha}^{-1}$ de B foliar no amendoim causou efeito depressivo na produtividade, rendimento e número de vagens por planta.
\end{abstract}

Palavras-chave: Arachis hypogaea, ácido bórico, adubação foliar.

\begin{abstract}
Boron leaf application at different growth stages of peanut

Boron leaf application to the peanut crop can be a viable strategy for supplying this element to the plant, however, knowledge os lacking on rate, time and dose split. The aim of this study was to evaluate the production and the leaf mineral composition at different rates, application times and split of boron fertilization. The experiment was conducted in the summer harvest 2010/2011 in an Oxisol in Rubiácea (SP). Leaf applications of boron rates of 0, 0.5, 1.0, 1.5 and 2.0 $\mathrm{kg} \mathrm{ha}^{-1}$ were tested using boric acid as source. The effects of boron fertilization were tested in single doses at the V1 and R5 growth stages, in addition to splitting the rate of $1 \mathrm{~kg} \mathrm{ha}^{-1}\left(0.5 \mathrm{~kg} \mathrm{ha}^{-1}\right.$ at V1 and R5), 1.5 ( $0.75 \mathrm{~kg} \mathrm{ha}^{-1}$ at V1 and $\mathrm{R} 5 ; 0.5 \mathrm{~kg} \mathrm{ha}^{-1}$ at V1, R1 and R5) and $2.0 \mathrm{~kg} \mathrm{ha}^{-1}\left(1.0 \mathrm{~kg} \mathrm{ha}^{-1}\right.$ at V1 and R5; $0.5 \mathrm{~kg} \mathrm{ha}^{-1}$ at V1, R1, R3 and R5). The increase in peanut yield occured only at the rate of $1.5 \mathrm{~kg} \mathrm{ha}^{-1}$ split in three applications of $0.5 \mathrm{~kg} \mathrm{ha}^{-1}$ at $\mathrm{V} 1, \mathrm{R} 1$ and R5. The leaf application of $2.0 \mathrm{~kg} \mathrm{ha}^{-1}$ of $\mathrm{B}$ to peanut cause a depressing effect on yield and number of pods per plant.
\end{abstract}

Key words: Arachis hypogaea, boric acid, leaf fertilization.

\footnotetext{
Recebido para publicação em 05/03/2012 e aprovado em 05/03/2013.

' Parte da Dissertação de mestrado apresentada pelo primeiro autor à Universidade do Oeste Paulista (UNOESTE).

${ }^{2}$ Engenheiro-Agrônomo, Mestre. Prefeitura da Estância Turística de Tupã, Praça da Bandeira, 800, 17600-900, Tupã, São Paulo, Brasil. jpmmantovani@ hotmail.com ${ }^{3}$ Engenheiro-Agrônomo, Doutor. Centro de Ciências Agrárias, Universidade do Oeste Paulista, Rodovia Raposo Tavares, Km 572, 19067-175, Presidente Prudente, São Paulo, Brasil.juliano@unoeste.br (autor correspondente).

${ }^{4}$ Engenheiro-Agrônomo, Doutor. Embrapa Soja, Rodovia Carlos João Strass, Acesso Orlando Amaral, 86001-970, Londrina, Paraná, Brasil. salvador.foloni@cnpso.embrapa.br
} 


\section{INTRODUÇÃO}

A partir de meados da década de 70 , houve intenso declínio da produção nacional de amendoim, influenciado por vários fatores, dentre eles a substituição das áreas por lavouras de soja. No entanto, com o crescimento da área de produção de cana-de-açúcar e a utilização do amendoim como opção de lavoura para reforma de canaviais (Freitas et al., 2005), houve um aumento da área cultivada e da produtividade, com produções oscilando entre 250 e 280 mil toneladas de grãos em casca, por ano, nas últimas safras (Conab, 2011).

A utilização das áreas de reforma de canavial para o cultivo de culturas graníferas possibilita o aumento da oferta de alimentos, em consonância com a expansão das áreas para a produção de etanol. No caso específico do amendoim, que se encontrava em pleno declínio de cultivo nas últimas décadas, observa-se a sua consolidação como leguminosa para renovação de canaviais, em diferentes regiões produtoras, o que tem possibilitado a estabilização da área de cultivo, com consistente reestruturação da sua cadeia produtiva e, inclusive, com incrementos expressivos de produtividade (Godoy, 2007).

O boro (B) participa de vários processos do metabolismo vegetal; portanto, a sua deficiência causa rápida inibição na formação de novos tecidos, em razão da função que exerce na composição da parede celular e na integridade da membrana plasmática (Cakmak \& Römheld, 1997), assim como na divisão celular (Dechen et al , 1991), na elongação celular, no metabolismo e transporte de carboidratos (Zhao \& Oosterhuis, 2002), na organização e funcionamento das membranas (Tanada, 1983), na germinação de grãos de pólen e no crescimento do tubo polínico (Agarwala et al., 1981).

Malavolta (2006) enfatiza que o B aumenta o pegamento de flores e a granação, em diferentes culturas, e propicia menor esterilidade masculina e menor chochamento de grãos. A exigência nutricional das plantas cultivadas torna-se, em geral, mais intensa com o início da fase reprodutiva, pois as lavouras encontram-se em pleno desenvolvimento vegetativo, somado à forte demanda por nutrientes para a formação das estruturas reprodutivas (Carvalho \& Nakagawa, 2000).

A carência de B é muito comum em solos tropicais, particularmente nos mais arenosos e pobres em matéria orgânica (Oliveira et al., 1996), o que tem provocado grandes perdas de produtividade em diferentes culturas (Mariano et al., 2000). No que diz respeito ao manejo da adubação boratada, as quantidades relativamente baixas de B exigidas pela cultura em geral podem ser satisfeitas por meio da adubação foliar. Porém, a baixa mobilidade do $\mathrm{B}$ nos tecidos vegetais pode constituir um entrave à nutrição da planta, fazendo que sejam necessárias várias aplicações. Por outro lado, ao contrário da adubação com micronutrientes via solo, a adubação foliar possibilita aplicações mais uniformes por unidade de área e respostas relativamente mais rápidas, quando as lavouras encontram-se em fases avançadas do seu desenvolvimento, sendo possível corrigir eventuais deficiências no curto prazo (Volkweiss, 1991).

As quantidades de B requeridas para a formação das sementes geralmente são maiores do que as necessárias para o crescimento vegetativo (Marschner, 1995). Por essa razão, mesmo em situações nas quais a cultura encontrase em solo com boas reservas de B, podem ser obtidos aumentos de produtividade com a adubação foliar (Rosolem, 1980). Além disso, como a maioria dos cultivos de amendoim é realizada em área de reforma de canavial, em geral os níveis de B do solo são baixos, em razão da forte exaustão promovida pelas sucessivas colheitas de cana.

O objetivo deste trabalho foi avaliar características de produção e a composição mineral foliar em diferentes doses, épocas de aplicação e parcelamento da adubação boratada.

\section{MATERIAL E MÉTODOS}

O experimento foi conduzido em área de renovação de canavial, no município de Rubiácea, SP, em Latossolo Vermelho-Escuro distroférrico (LVedf) (Embrapa, 2006), no período de Novembro de 2010 a Março de 2011. O clima da região, segundo a classificação de Koppen, é do tipo Cwa, com temperaturas médias anuais em torno de $25^{\circ} \mathrm{Ce}$ regime pluvial caracterizado por dois períodos distintos, sendo um chuvoso, de outubro a março, e outro de baixa precipitação pluvial, de abril a setembro.

Foram coletados diariamente dados de volume de chuva e de temperatura média, para caracterizar as condições do clima no decorrer da condução do experimento (Figura 1). Antes de iniciar o experimento, amostras de solo foram coletadas nas camadas de 0 a 20 e 20 a 40 $\mathrm{cm}$, para caracterização da fertilidade do solo (Raij et al., 2001) (Tabela 1).

Em torno de 40 dias antes do início do experimento, a área recebeu calcário dolomítico, para elevar a saturação por bases a $70 \%$ e $1 \mathrm{Mg} \mathrm{ha}^{-1}$ de gesso agrícola, os quais foram incorporados ao solo por meio de aração e gradagem. Em seguida, por ocasião da semeadura, o solo foi submetido a uma segunda gradagem niveladora. Por se tratar de uma área de reforma de canavial, a correção com calagem e gessagem seguiu recomendações de Raij et al. (1997) para a cultura da cana-de-açúcar. $\mathrm{O}$ amendoim foi semeado em 10/11/2010, utilizando-se o cultivar IAC Runner 886, do grupo rasteiro e tardio, semeado com espaçamento entrelinhas de $0,90 \mathrm{~m}, 18$ sementes viáveis $\mathrm{m}^{-2}$ e aplicação 


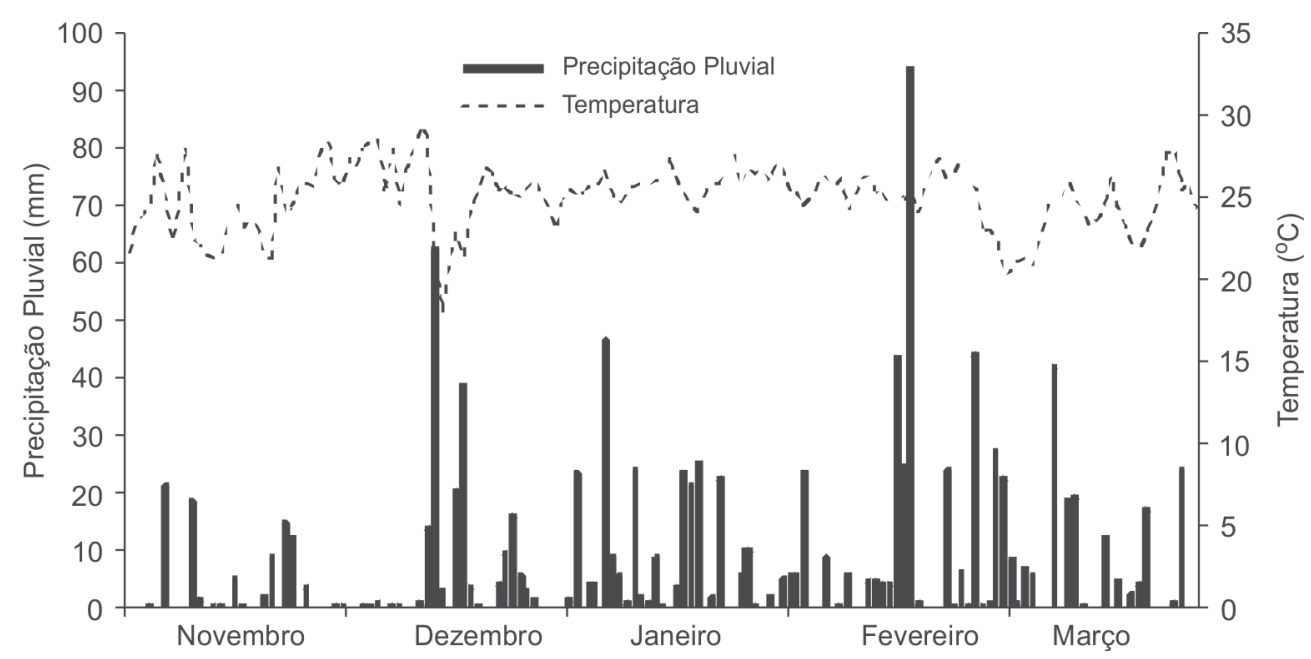

Figura 1. Dados diários de temperatura média e precipitação pluvial durante o período de condução da cultura no campo (Novembro de 2010 a Março de 2011).

Tabela 1. Propriedades químicas nas camadas de 0 a 20 e de 20 a $40 \mathrm{~cm}$ do solo antes da instalação do experimento

\begin{tabular}{lcc}
\hline Atributo do solo & $\mathbf{0 ~ a ~ 2 0 ~ c m ~}$ & $\mathbf{2 0}$ a $\mathbf{4 0} \mathbf{~ c m}$ \\
\hline $\mathrm{P}_{\text {resina }}\left(\mathrm{mg} \mathrm{dm}^{-3}\right)$ & 2 & 1 \\
$\mathrm{MO}\left(\mathrm{g} \mathrm{dm}^{-3}\right)$ & 12 & 7 \\
$\mathrm{pH}\left(\mathrm{CaCl}_{2}\right)$ & 4,3 & 4,0 \\
$\mathrm{~K}\left(\mathrm{mmol}_{\mathrm{c}} \mathrm{dm}^{-3}\right)$ & 1,1 & 0,8 \\
$\mathrm{Ca}\left(\mathrm{mmol}_{\mathrm{c}} \mathrm{dm}^{-3}\right)$ & 13 & 9 \\
$\mathrm{Mg}\left(\mathrm{mmol}_{\mathrm{c}} \mathrm{dm}^{-3}\right)$ & 7 & 2 \\
$\mathrm{H}+\mathrm{Al}\left(\mathrm{mmol}_{\mathrm{c}} \mathrm{dm}^{-3}\right)$ & 16 & 16 \\
$\mathrm{CTC}\left(\mathrm{mmol}_{\mathrm{c}} \mathrm{dm}^{-3}\right)$ & 37 & 28 \\
$\mathrm{~V}(\%)$ & 57 & 42 \\
$\mathrm{~B}\left(\mathrm{mg} \mathrm{dm}^{-3}\right)$ & 0,12 & 0,07 \\
$\mathrm{Cu}\left(\mathrm{mg} \mathrm{dm}^{-3}\right)$ & 0,15 & 0,05 \\
$\mathrm{Fe}\left(\mathrm{mg} \mathrm{dm}^{-3}\right)$ & 22 & 14 \\
$\mathrm{Mn}\left(\mathrm{mg} \mathrm{dm}^{-3}\right)$ & 9.7 & 5,2 \\
$\mathrm{Zn}\left(\mathrm{mg} \mathrm{dm}^{-3}\right)$ & 1,1 & 0,4 \\
\hline
\end{tabular}

de $230 \mathrm{~kg} \mathrm{ha}^{-1}$ do adubo formulado NPK 04-30-10, com estande final da lavoura da ordem de 167.000 plantas ha $^{-1}$.

Foi realizado tratamento das sementes com fungicida e inseticida, assim como foi adotado um manejo fitossanitário, no decorrer da condução do experimento, a partir de indicações de Gallo et al. (2002), Barreto (2005) e Agrofit (2010), para o que se considerou o histórico de ocorrência regional e o monitoramento periódico de pragas, doenças e plantas daninhas, associado a critérios de nível de dano econômico.

O delineamento experimental foi em blocos casualizados, com quatro repetições, nos quais foram instalados 14 tratamentos de adubação boratada, com doses de zero (controle), 0,5, 1,0, 1,5 e 2,0 $\mathrm{kg} \mathrm{ha}^{-1}$ de B (fonte ácido bórico), aplicadas em única vez, ou de maneira parcelada, entre 30 e 75 dias após a emergência das plantas (DAE), ou seja, entre os estádios fenológicos V1 e R5 da cultura, constituindo os tratamentos apresentados na Tabela 2.
As parcelas experimentais foram constituídas por quatro linhas de plantas, com $8 \mathrm{~m}$ de comprimento, e a área útil foi definida pelas duas linhas centrais, com $6 \mathrm{~m}$ de comprimento $\left(10,8 \mathrm{~m}^{2}\right)$. As aplicações foliares de B foram realizadas, utilizando-se pulverizador pressurizado com $\mathrm{CO}_{2}$, operando à pressão constante de $150 \mathrm{kPa}$, munido de barra de aplicação com quatro bicos jato plano, do tipo leque, modelo 110.04 , espaçados em $0,50 \mathrm{~m}$, que proporcionaram volume de calda equivalente a $200 \mathrm{~L} \mathrm{ha}^{-1}$.

Cinco dias após a última aplicação de B na cultura, período em que as plantas se encontravam em pleno florescimento (79 DAE), fez-se a coleta, ao acaso, do tufo apical do ramo principal de 30 plantas, na área útil das parcelas, para determinação de teores de macro e micronutrientes, seguindo-se a metodologia de Raij et al. (1997). As folhas foram secadas a $65^{\circ} \mathrm{C}$, em estufa de circulação forçada de ar, por 72 horas, trituradas em moinho tipo Wiley e encaminhadas ao laboratório de análise de plantas, da Universidade do Oeste Paulista, Presidente Prudente (SP), para análise dos teores de macro e micronutrientes, segundo metodologia proposta por Malavolta et al. (1997).

A colheita foi realizada aos 139 DAE. Por ocasião da colheita, foram arrancadas todas as plantas contidas em dois metros contíguos das duas linhas centrais de cada parcela. Em seguida, essas plantas foram deixadas para secagem no campo, trilhagem por abanação manual, para contagem do número de vagens por planta e pesagem da massa de vagens antes da debulha. Após a debulha manual, fez-se a contagem do número de grãos por vagem e a determinação da massa de grãos, para cálculo de produtividade, além da determinação da massa de 100 grãos (Brasil, 2009). O rendimento de grãos foi determinado mediante a relação da massa de grãos/massa de vagens, em percentagem. $\mathrm{O}$ teor de água dos grãos foi corrigido para $8 \%$ e os resultados de produtividade foram expressos em $\mathrm{kg} \mathrm{ha}^{-1}$. 
Tabela 2. Doses de B e forma de parcelamento da adubação em função dos estádios fenológicos da cultura do amendoim

\begin{tabular}{lcl}
\hline Tratamento & Dose $\left(\mathbf{k g ~ h a}^{-\mathbf{1}}\right)$ & Época de aplicação em função do estádio fenológico* \\
\hline 1 & zero & - \\
2 & 0,5 & $100 \% \mathrm{~V} 3$ \\
3 & 0,5 & $100 \% \mathrm{R} 5$ \\
4 & 1,0 & $100 \% \mathrm{~V} 3$ \\
5 & 1,0 & $100 \% \mathrm{R} 5$ \\
6 & 1,0 & $50 \% \mathrm{~V} 3+50 \% \mathrm{R} 5$ \\
7 & 1,5 & $100 \% \mathrm{~V} 3$ \\
8 & 1,5 & $100 \% \mathrm{R} 5$ \\
9 & 1,5 & $50 \% \mathrm{~V} 3+50 \% \mathrm{R} 5$ \\
10 & 1,5 & $33 \% \mathrm{~V} 3+33 \% \mathrm{R} 1+33 \% \mathrm{R} 5$ \\
11 & 2,0 & $100 \% \mathrm{~V} 3$ \\
12 & 2,0 & $100 \% \mathrm{R} 5$ \\
13 & 2,0 & $50 \% \mathrm{~V} 3+50 \% \mathrm{R} 5$ \\
14 & 2,0 & $25 \% \mathrm{~V} 3+25 \% \mathrm{R} 1+25 \% \mathrm{R} 3+25 \% \mathrm{R} 5$ \\
\hline
\end{tabular}

*V3 = 30 dias após emergência (DAE); R1 = 45 DAE; R3 = 60 DAE; R5 = 75 DAE.

Os dados foram submetidos à análise de variância e as médias comparadas por meio do teste de Tukey a 5\% de probabilidade. As respostas das variáveis analisadas em função das doses de B aplicadas foram submetidas à análise de regressão, sendo ajustados modelos matemáticos significativos a $5 \%$ de probabilidade, pelo teste $\mathrm{F}$, por meio do software SigmaPlot 10.0.

\section{RESULTADOS E DISCUSSÃO}

Os tratamentos envolvendo adubação boratada foliar aumentaram o teor de $\mathrm{N}$ nas folhas de amendoim, em relação ao mesmo teor no tratamento testemunha $\left(0 \mathrm{~kg} \mathrm{ha}^{-1} \mathrm{de}\right.$ B). No entanto, não houve diferença significativa entre as doses de 0,$5 ; 1,0 ; 1,5$ e 2,0 $\mathrm{kg} \mathrm{ha}^{-1} \mathrm{de} \mathrm{B}$, independentemente da época de aplicação ou da forma de parcelamento (Figura 2A). O teor de N foliar apresentou comportamento quadrático, em função das doses de $\mathrm{B}$, com máximo teor $\left(42,4 \mathrm{~g} \mathrm{~kg}^{-1}\right.$ de N) com a dose estimada de $1,7 \mathrm{~kg} \mathrm{ha}^{-1}$ de B. Segundo Malavolta et al. (1997), o B tem importante função na assimilação de $\mathrm{N}$, já que é fundamental para a síntese de ácidos nucleicos e proteínas e para atividade fotossintética e metabolismo de carboidratos. Por essa razão, por ser uma leguminosa com elevado potencial de fixação simbiótica de $\mathrm{N}$, a deficiência de $\mathrm{B}$ pode afetar a atividade dos micro-organismos fixadores de $\mathrm{N}$, levando à deficiência de $\mathrm{N}$ no amendoim. No entanto, Calonego et al. (2011) não observaram incremento no teor de $\mathrm{N}$ nas folhas de soja, em função de doses crescentes de B aplicadas por via foliar.

Para os demais macronutrientes, não se observaram diferenças entre os tratamentos nos teores nas folhas, porém verificaram-se comportamentos lineares e quadráticos para os teores de Ca (Figura 2B) e S (Figura 2C), respectivamente. De acordo com as faixas de teores de macronutrientes, consideradas por Raij et al. (1997) como adequados para a cultura do amendoim, observa-se que os teores de $\mathrm{P}$ ficaram abaixo do limite mínimo de $2,0 \mathrm{~g} \mathrm{~kg}^{-1}$, em todos os tratamentos estudados (Figura 2D), e os tratamentos com 0 e $0,5 \mathrm{~kg} \mathrm{ha}^{-1} \mathrm{de} \mathrm{B}$, aplicados no estádio $\mathrm{V} 1$, proporcionaram teores de $\mathrm{S}$ abaixo de $2,0 \mathrm{~g} \mathrm{~kg}^{-1}$, também considerado como teor mínimo para o ótimo desenvolvimento do amendoim.

Esperava-se que, com a adubação boratada, houvesse aumento no teor de K e P nas folhas, já que, segundo Power \& Woods (1997), a absorção de K aumenta com o fornecimento de B e quase não ocorre na sua ausência, além de o B auxiliar no transporte de $\mathrm{P}$ através das membranas. Cakmak et al. (1995) comprovaram que, por causa de o B garantir a integridade da membrana plasmática, houve efluxo 45 vezes maior de $\mathrm{K}$ em folhas de girassol, deficientes em $\mathrm{B}$, em relação às folhas bem nutridas. Segundo Dechen \& Nachtigall (2006), o B interfere na absorção e no metabolismo dos cátions, assim como observado por Souza et al. (2011), com aumento no teor de Mg na parte aérea do feijão, em função do aumento da dose de B.

Os teores de micronutrientes não foram afetados pela adubação boratada foliar (Figura 3), com exceção do próprio $\mathrm{B}$, que aumentou de forma linear com o aumento da dose aplicada (Figura 3A). O menor teor de B foi obtido com o tratamento testemunha $\left(0 \mathrm{~kg} \mathrm{ha}^{-1} \mathrm{de} \mathrm{B}\right)$, sem diferir significativamente do teor com o tratamento com aplicação de $0,5 \mathrm{~kg} \mathrm{ha}^{-1}$ de B em V1. Por outro lado, os maiores teores de B nas folhas foram obtidos com a aplicação de 2,0 $\mathrm{kg} \mathrm{ha}^{-1}$ de B, porém sem diferir do tratamento com 1,5 $\mathrm{kg} \mathrm{ha}^{-1}$, parcelado em três aplicações $(33 \%$ em V1 + 33\% em R1 + 33\% em R5). No entanto, todos os tratamentos proporcionaram teores de B dentro da faixa indicada como ótima para a cultura, que, segundo Raij et al. (1997), é de 25 a $60 \mathrm{mg} \mathrm{kg}^{-1}$. Por essa razão, pode-se dizer que não 
houve deficiência de B no amendoim, mesmo com a ausência de adubação com esse micronutriente. Quanto aos outros micronutrientes, apenas o Fe apresentou-se com teores abaixo da faixa ideal (50 a $300 \mathrm{mg} \mathrm{kg}^{-1}$ ), para o tratamento testemunha (Figura 3B).

$\mathrm{O}$ teor de B nas folhas aumentou de forma linear em função das doses aplicadas, com amplitude entre 28,8 e $51,5 \mathrm{mg} \mathrm{kg}^{-1}$, situando-se o teor ótimo para a máxima produtividade em torno de 43,9 $\mathrm{mg} \mathrm{kg}^{-1}$ (Figura 4). Para a cultura do café, Santinato et al. (1991) e Marubayashi et al. (1994) não encontraram correlação entre teor foliar de
B e produtividade de café, ao contrário dos resultados obtidos por Lima Filho \& Malavolta (1992) e Barros et al. (1996). Boaretto et al. (1997) citam que muitas vezes a não correlação entre os teores de B nas folhas e a produtividade pode ser explicada pela dificuldade da planta em remover o boro retido na cutícula foliar ou ligado à camada péctica da parede celular, sem concretizar sua função metabólica, superestimando, assim, o nível de B foliar. Rosolem et al. (2008) também não encontraram uma relação entre os teores de B nas folhas de soja e a produtividade de grãos.
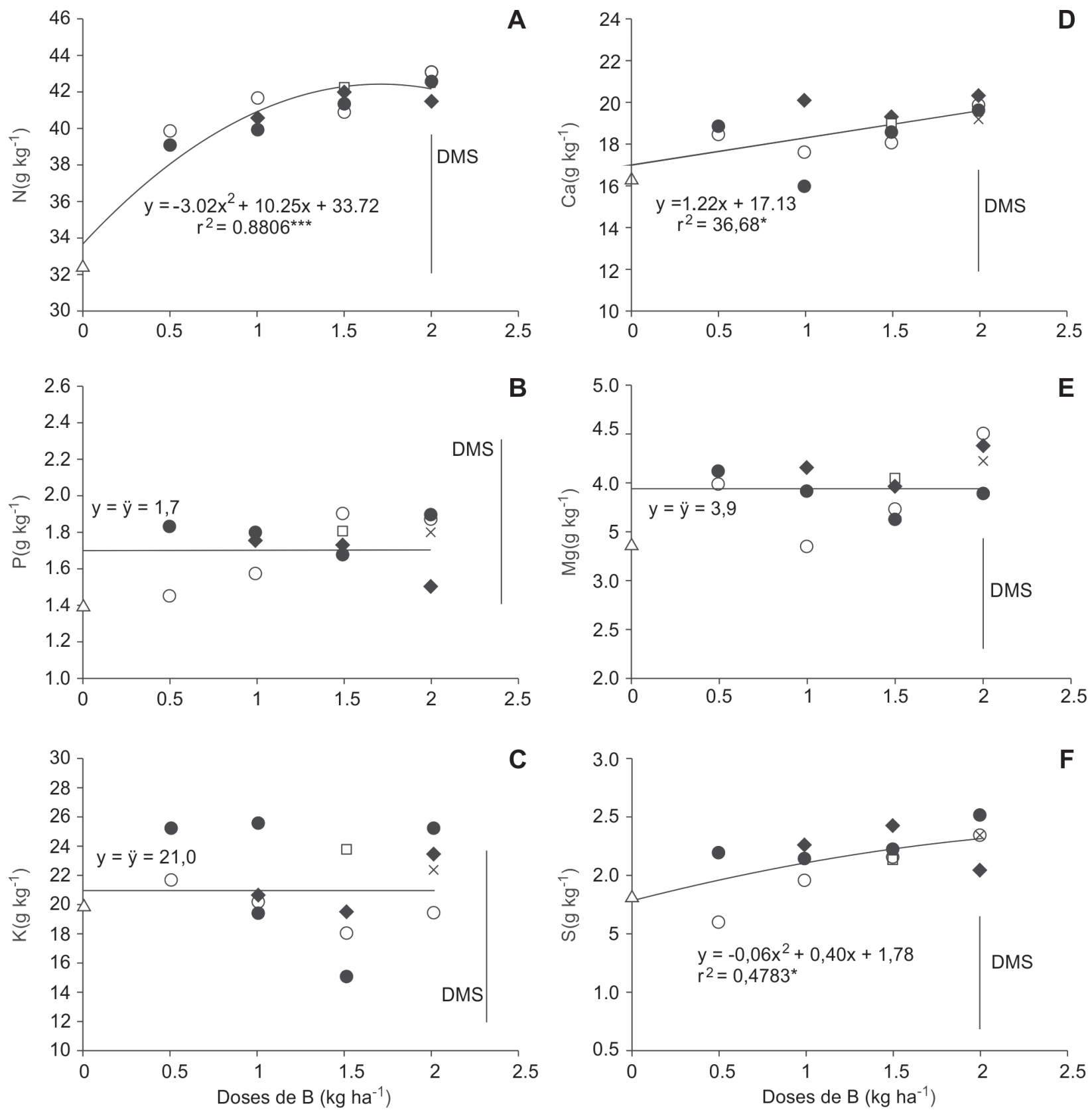

Figura 2. Teores de N (A), Ca (B), S (C), P (D), Mg (E) e K (F), em g kg-1, em função das doses zero, 0,5, 1,0, 1,5 e 2,0 kg ha-1 de B. (o) 100\% em V1; (Ï\%) 100\% em R5; (४) 50\% em V1 + 50\% em R5; (ㅁ) 33\% em V1 + 33\% em R1 + 33\% em R5; (×) 25\% em V1 + $25 \%$ em R1 + 25\% em R3 + 25\% em R5; ***Significativo a 5 e $1 \%$ de probabilidade pelo teste F, respectivamente. DMS: Diferença mínima significativa pelo teste de Tukey a $5 \%$ de probabilidade.

Rev. Ceres, Viçosa, v. 60, n.2, p. 270-278, mar/abr, 2013 
Entre os componentes da produção avaliados, a massa de 100 grãos (Figura 5A) e o número de grãos por vagem (Figura 5B) não foram afetados pela adubação boratada foliar, assim como constatado por Calonego et al. (2011) para a cultura da soja. $\mathrm{O}$ tratamento, envolvendo a dose de 1,5 $\mathrm{kg} \mathrm{ha}^{-1}$ com parcelas de $0,5 \mathrm{~kg} \mathrm{ha}^{-1}$, em V1, R1 e R5, aumentou o rendimento, ou seja, a massa de grãos em relação ao total de massa do fruto (Figura 5C). O número de vagens por planta em função das doses de B aplicadas (Figura 5D) ajustou-se a um modelo quadrático, com máxima produção de vagens com a dose estimada de $1,2 \mathrm{~kg} \mathrm{ha}^{-1}$. No entanto, as únicas diferenças significativas foram entre o tratamento com $1,5 \mathrm{~kg} \mathrm{ha}^{-1}$, parcelado em três aplicações, de $0,5 \mathrm{~kg} \mathrm{ha}^{-1}$ (em V1, R1 e R5) e o tratamento testemunha.
De forma geral, as produtividades obtidas neste experimento foram altas, atingindo $5254 \mathrm{~kg} \mathrm{ha}^{-1}$, no tratamento com aplicação de $1,5 \mathrm{~kg} \mathrm{ha}^{-1}$ de B, parcelado em três aplicações de 0,5 $\mathrm{kg} \mathrm{ha}^{-1}$ (em V1, R1 e R5), ou seja, muito acima dos $3100 \mathrm{~kg} \mathrm{ha}^{-1}$, que corresponde à média do Estado de São Paulo (Conab, 2011), e acima dos $4000 \mathrm{~kg} \mathrm{ha}^{-1}$, a média de produtividade para amendoim do tipo Runner (Freitas et al., 2005). A produtividade de amendoim em casca apresentou comportamento não linear, verificado pela análise de regressão, com pico de produção na dose de $1,5 \mathrm{~kg} \mathrm{ha}^{-1}$ (Figura 5E). Os tratamentos envolvendo essa dose de B não diferiram entre si quanto à produtividade de grãos; no entanto, foram superiores quanto às produções obtidas com o
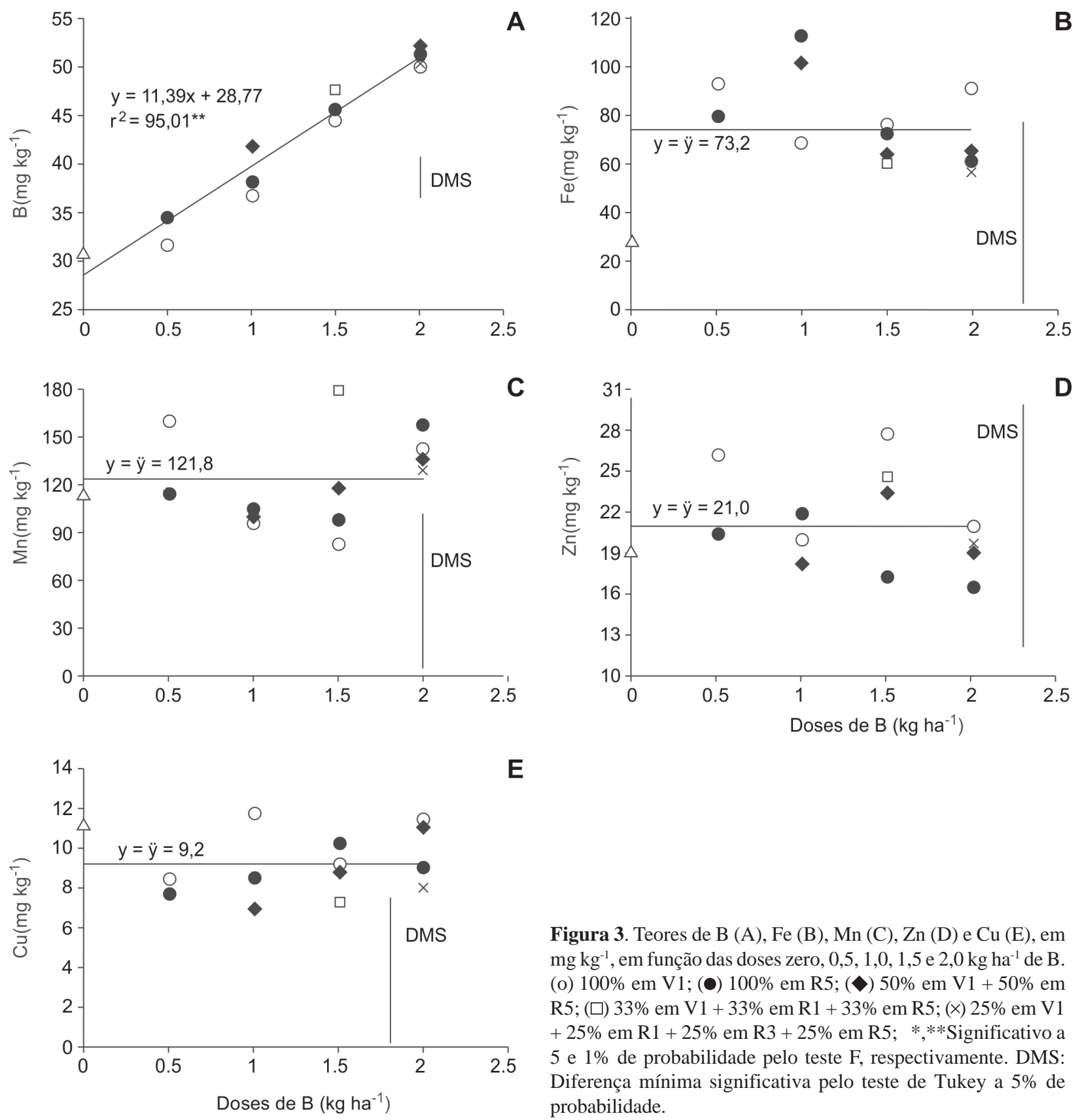

Figura 3. Teores de B (A), Fe (B), Mn (C), Zn (D) e Cu (E), em $\mathrm{mg} \mathrm{kg}{ }^{-1}$, em função das doses zero, $0,5,1,0,1,5$ e 2,0 $\mathrm{kg} \mathrm{ha}^{-1} \mathrm{de}$ B. (o) $100 \%$ em V1; (•) 100\% em R5; ( ) $50 \%$ em V1 + 50\% em R5; (ㅁ) 33\% em V1 + 33\% em R1 + 33\% em R5; (×) 25\% em V1 $+25 \%$ em R1 + 25\% em R3 + 25\% em R5; *** Significativo a 5 e $1 \%$ de probabilidade pelo teste F, respectivamente. DMS: Diferença mínima significativa pelo teste de Tukey a $5 \%$ de probabilidade. 


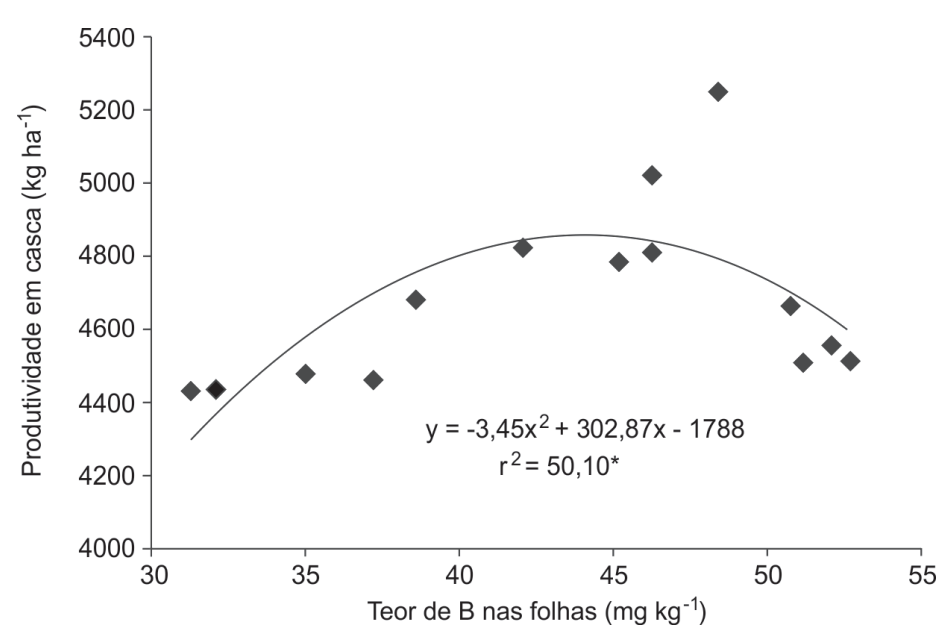

Figura 4. Relação entre os teores de $B$ nas folhas do amendoim $\left(\mathrm{mg} \mathrm{kg}^{-1}\right)$ e a produtividade de amendoim em casca $\left(\mathrm{kg} \mathrm{ha}^{-1}\right)$. *Significativo a $5 \%$ de probabilidade pelo teste $\mathrm{F}$.
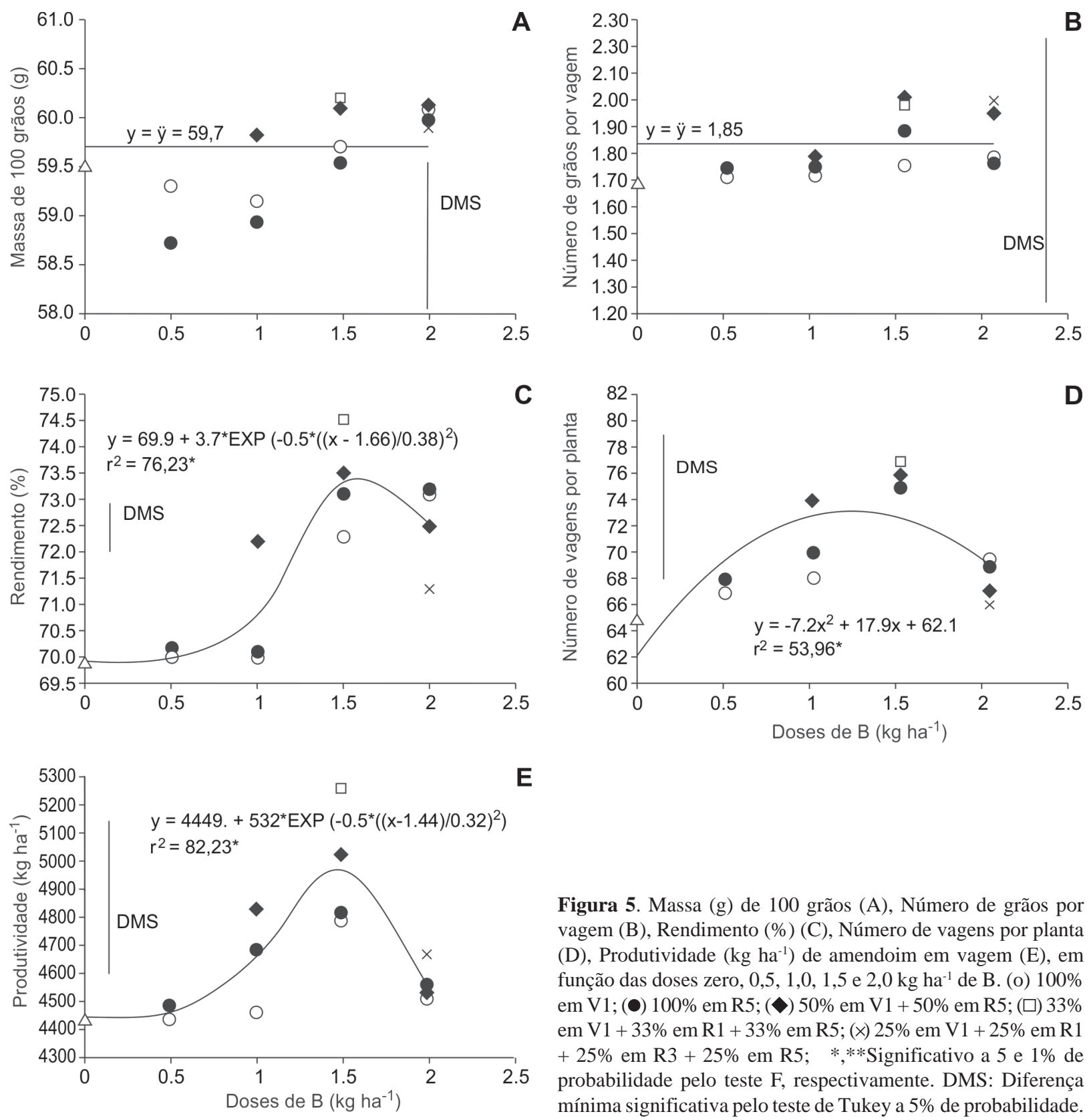

E

Figura 5. Massa (g) de 100 grãos (A), Número de grãos por vagem (B), Rendimento (\%) (C), Número de vagens por planta (D), Produtividade $\left(\mathrm{kg} \mathrm{ha}^{-1}\right)$ de amendoim em vagem (E), em função das doses zero, $0,5,1,0,1,5$ e $2,0 \mathrm{~kg} \mathrm{ha}^{-1} \mathrm{de}$ B. (o) $100 \%$

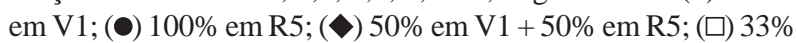
em V1 + 33\% em R1 + 33\% em R5; (x) 25\% em V1 + 25\% em R1 $+25 \%$ em R3 + 25\% em R5; *** Significativo a 5 e $1 \%$ de probabilidade pelo teste $\mathrm{F}$, respectivamente. DMS: Diferença mínima significativa pelo teste de Tukey a 5\% de probabilidade.

Rev. Ceres, Viçosa, v. 60, n.2, p. 270-278, mar/abr, 2013 
tratamento testemunha, além daquelas com os tratamentos envolvendo 0,5 e 2,0 $\mathrm{kg} \mathrm{ha}^{-1}$ de $\mathrm{B}$, e das com os tratamentos com 1,0 $\mathrm{kg} \mathrm{ha}^{-1}$, em dose única, em V1 ou R5. Porém, não se observou diferença em relação à dose de $1,0 \mathrm{~kg} \mathrm{ha}^{-1}$ de B aplicado parceladamente, com $50 \%$ em V1 e 50\% em R5.

Apesar de Rosolem \& Costa (2000) constatarem que o B, aplicado por via foliar no algodoeiro, não é translocado do local de aplicação para as demais partes da planta, denotando uma mobilidade restrita desse nutriente nestas plantas, Carvalho et al. (1996) obtiveram aumentos de produtividade de algodão com aplicações foliares de B. Bevilaqua et al. (2002) também afirmam que a aplicação foliar de B pode aumentar o número de vagens e a massa de sementes por planta, quando realizada na fase de floração. Rosolem \& Boaretto (1989), estudando os efeitos da adubação com B na soja, constataram que a época de maior demanda de nutrientes pelas plantas é entre R1 e R5. Assim, por ser o B pouco móvel no floema, pode-se afirmar que a aplicação deste nutriente deve ser feita de forma parcelada, durante a floração e pós-floração e, no caso do amendoim esse parcelamento deverá ser ainda maior, já que se trata de uma cultura com florescimento desuniforme (Tasso Júnior et al., 2004).

Volkweiss (1991) e Tanaka \& Mascarenhas (1992) também relataram a necessidade de parcelamento da aplicação de B por via foliar, pela baixa mobilidade desse nutriente no interior do floema, pois forma complexos de baixa solubilidade e, portanto, de difícil redistribuição das folhas mais maduras para os pontos de maior exigência como os tecidos meristemáticos. Segundo os autores, isto implica a necessidade de uma constante disponibilidade ou suprimento desse nutriente durante toda a fase de desenvolvimento das plantas. Porém, os resultados obtidos neste experimento comprovam que, para doses excessivas de $\mathrm{B}$, haverá efeito depressivo na produtividade de amendoim, mesmo com o parcelamento da dose durante o ciclo da cultura (Figura 5A).

\section{CONCLUSÕES}

A produtividade de amendoim em casca aumentou com a dose de 1,5 $\mathrm{kg} \mathrm{ha}^{-1}$, parcelada em três aplicações de 0,5 $\mathrm{kg} \mathrm{ha}^{-1} \mathrm{em}$ V1, R1 e R5.

A aplicação de B foliar em dose única, no préflorescimento ou no florescimento pleno do amendoim, não alterou a produtividade, independentemente da dose utilizada.

A utilização de $2,0 \mathrm{~kg} \mathrm{ha}^{-1}$ de $\mathrm{B}$ foliar causou efeito depressivo na produtividade de amendoim em casca, rendimento e número de vagens por planta, mesmo com o parcelamento da dose.

\section{REFERÊNCIAS}

Agarwala SC, Sharma PN, Chatterjee C \& Sharma CP (1981) Development and enzymatic changes during pollen development in boron deficient maize plants. Journal Plant Nutrition, 3:329336.

Agrofit (2010) Sistema de agrotóxicos fitossanitários. Disponível em: <http://afrofit.agricultura.gov.br/agrofit_cons/ principal_agrofit_cons>. Acessado em 05: de novembro de 2010.

Barreto M (2005) Doenças do amendoim. In: Kimati H, Amorim L, Rezende JAM, Bergamin Filho A \& Camargo LEA (Eds.) Manual de fitopatologia - doenças de plantas cultivadas. (4 Ed.). São Paulo, Agronômica Ceres. p.65-72.

Barros UV, Santinato R \& Matiello JB (1996) Fontes, doses e método de aplicação de B no plantio de café na região da Zona da Mata em Minas Gerais. In: $22^{\circ}$ Congresso Brasileiro de Pesquisas Cafeeiras, Águas de Lindóia. Anais, Ministério da Agricultura e do Abastecimento. p.117-118.

Bevilaqua GAP, Silva Filho PM \& Possenti JC (2002) Aplicação foliar de cálcio e boro e componentes de rendimento e qualidade de sementes de soja. Ciência Rural, 32:31-34.

Boaretto AE, Tiritan CS \& Muraoka T (1997) Effects of foliar applications of boron on citrus fruit and on foliage and soil boron concentration. In: Bell RW \& Rerkasem B (Eds.) Boron in Soils and Plants. Dordrecht, Kluwer Academic Publishers. p.121-123.

Brasil (2009) Ministério da Agricultura, Pecuária e Abastecimento. Regras para análise de sementes. Ministério da Agricultura, Pecuária e Abastecimento. Secretaria de Defesa Agropecuária. Brasília, Mapa/ACS. 399p.

Cakmak I, Kurz H \& Marschner H (1995) Short-term effects of boron, germanium and high light intensity on membrane permeability in boron deficient leaves of sunflower. Physiologia Plantarum, 95:11-18.

Cakmak I \& Römheld V (1997) Boron deficiency induced impairments of cellular functions in plants. Plant and Soil, 193:71-83.

Calonego JC, Ocani KP, Ocani MP \& Santos CH (2011) Adubação boratada foliar na cultura da soja. Colloquium Agrariae, 6:20-26.

Carvalho NM \& Nakagawa J (2000) Sementes: ciência, tecnologia e produção. $4^{\mathrm{a}}$ ed. Jaboticabal, Funep. 588p.

Carvalho LH, Silva NM, Brasil Sobrinho MOC, Kondo JI \& Chiavegato EJ (1996) Aplicação de boro no algodoeiro, em cobertura e em pulverização foliar. Revista Brasileira de Ciência do Solo, 20:265-266.

Conab (2011) Companhia Nacional de Abastecimento. Séries Históricas. Disponível em: http://www.conab.gov.br. Acessado em: 20 de novembro de 2011.

Dechen AR, Haag HP \& Carmello QA de C (1991) Funções dos micronutrientes nas plantas. In: Ferreira ME \& Cruz MCP (Eds.) Micronutrientes na Agricultura. Piracicaba, Potafos/ CNPq. p.65-97.

Dechen AR \& Nachtigall GR (2006) Micronutrientes. In: Fernandes MS (Ed.) Nutrição mineral de plantas. Viçosa, Sociedade Brasileira de Ciência do Solo. p.327-354.

Embrapa (2006) Centro Nacional de Pesquisa de Solos. Sistema brasileiro de classificação de solos. Rio de Janeiro, Embrapa. $306 \mathrm{p}$.

Freitas SM de, Martins SS, Nomi AK \& Campos AF (2005) Evolução do mercado brasileiro de amendoim. In: Santos RC dos (Ed.) O Agronegócio do Amendoim no Brasil. Campina Grande, EMBRAPA. p.16-44.

Rev. Ceres, Viçosa, v. 60, n.2, p. 270-278, mar/abr, 2013 
Gallo D, Nakano O, Silveira Neto S, Carvalho RPL, Baptista GC de, Berti Filho E, Parra JRP, Zucchi RA, Alves SB, Vendramim JD, Marchini LC, Lopes JRS \& Omoto C (2002) Entomologia Agrícola. Piracicaba, FEALQ. 920p.

Godoy IN (2007) Importância dos fertilizantes na cultura do amendoim. São Paulo, Agronômica Ceres. 734p.

Lima Filho OF \& Malavolta E (1992) Calibração de boro e zinco para o cafeeiro (Coffea arabica L. cv. Catuaí Amarelo). In: 20 Reunião Brasileira de Fertilidade do Solo e Nutrição de Plantas, Piracicaba. Anais, SBCS. p.54-55.

Malavolta E, Vitti GC \& Oliveira AS (1997) Avaliação do estado nutricional de plantas: Princípios e aplicações. Piracicaba Potafós. 308p.

Malavolta E (2006) Manual de nutrição mineral de plantas. São Paulo, Agronômica Ceres. 638p.

Mariano ED, Faquin V, Neto AEF, Andrade AT \& Mariano IO (2000) Níveis críticos de boro em solos de várzea para o cultivo do feijoeiro. Pesquisa Agropecuária Brasileira, 35:1637-1644.

Marubayashi OM, Pedroso PAC, Vitti GC \& Costa WM (1994) Efeito de fontes e formas de aplicação de boro e zinco na cultura do cafeeiro. Científica, 22:289-99.

Marschner H (1995) Mineral nutrition of higher plants. San Diego, Academic Press. 889p.

Oliveira IP, Araújo RS \& Dutra LG (1996) Nutrição mineral e fixação biológica de nitrogênio. In: Araújo RS, Rava CA, Stone LF \& Zimmermann MJO (Eds.) Cultura do feijoeiro comum no Brasil. Piracicaba, Potafos. p.301-52.

Power PP \& Woods WG (1997) The chemistry of boron and its speciation in plants. In: Dell B, Rown PH \& Bell RW (Eds.) Boron in soil and plants: reviews. Dordrecht, Kluwer Academic Publishers. p.1-14

Raij B van, Silva NM, Cantarella H, Quaggio JA \& Furlani AMC (1997) Recomendações de adubação e calagem para o Estado de São Paulo. $2^{a}$ ed. Campinas, Instituto Agronômico. 285p.
Raij B van, Andrade JC, Cantarella H \& Quaggio JA (2001) Análise química para avaliação da fertilidade de solos tropicais. Campinas, Instituto Agronômico. 284p.

Rosolem, CA (1980) Nutrição mineral e adubação de soja. Piracicaba, Potafós. 80p. (Boletim técnico, 6).

Rosolem CA \& Boaretto AE (1989) A adubação foliar em soja. In: Boaretto AE \& Rosolem CA (Eds.) Adubação foliar. Campinas, Fundação Cargill. 500p.

Rosolem CA \& Costa A (2000) Cotton growth and boron distribution in the plants as affected by a temporary deficiency of boron. Journal of Plant Nutrition, 23:815-825.

Rosolem CA, Zancanaro L \& Biscaro T (2008) Boro disponível e resposta da soja em latossolo vermelho-amarelo do Mato Grosso. Revista Brasileira de Ciência do Solo, 32:2375-2383.

Santinato R, Sena CA, Silva AA \& Camargo RP (1991) Efeitos de P, $\mathrm{Ca}$ e B via foliar no pegamento de florada e frutificação do cafeeiro. In: $17^{\circ}$ Congresso Brasileiro de Pesquisas Cafeeiras, Espírito Santo do Pinhal. Anais, Instituto Brasileiro do Café. p.36-38.

Souza HA de, Natale W, Rozane DE, Hernandes A \& Romualdo LM (2011) Calagem e adubação boratada na produção de feijoeiro. Revista Ciência Agronômica, 42:249-257.

Tanada T (1983) Localization of boron in membranes. Journal of Plant Nutrition, 6:743-749.

Tanaka RT \& Mascarenhas HAA (1992) Soja. Nutrição, correção do solo e adubação. Campinas, Fundação Cargill. 60p. (Série Técnica, 7)

Tasso Júnior LC, Marques MO \& Nogueira G de A (2004) A cultura do amendoim. Jaboticabal, Unesp. 218p.

Volkweiss SJ (1991) Fontes e métodos de aplicação. In: Simpósio sobre Micronutrientes na agricultura, Jaboticabal. Anais, Potafós/ CNPq. p.391-412.

Zhao D \& Oosterhuis DM (2002) Cotton carbon exchange, nonstructural carbohydrates, and boron distribution in tissues during development of boron deficiency. Field Crops Research, 78:75-87. 